\title{
Trabecular bone area and bone healing in spontaneously hypertensive rats. A histometric study
}

\section{Marta Ferreira Bastos ${ }^{(a)}$ Felipe Vilhena Brilhante ${ }^{(b)}$ Joyce Pinho Bezerra ${ }^{(b)}$ Carlos Alberto Silva ${ }^{(c)}$ Poliana Mendes Duarte(a)}

(a) PhD, Assistant Professor; (b) MS program - Department of Periodontics, Dental Research Division, Guarulhos University, Guarulhos, SP, Brazil.

(c) $\mathrm{PhD}$, Assistant Professor, Department of Rehabilitation Sciences, Nove de Julho University, São Paulo, SP, Brazil.

\author{
Corresponding author: \\ Marta Ferreira Bastos \\ Praça Tereza, n. 229 - $1^{\circ}$ Andar - Centro \\ Guarulhos - SP - Brazil \\ CEP: 07023-070 \\ E-mail:mfbastos@prof.ung.br
}

Received for publication on Sep 01, 2009 Accepted for publication on Apr 12, 2010

\begin{abstract}
Clinical and experimental studies have demonstrated some negative effect of hypertension on bone mineral density. The aim of this study was to evaluate bone healing and trabecular bone area (TBA) in spontaneously hypertensive rats (SHR), a well-established model of essential hypertension, when compared to normotensive rats (NTR). A critical-size defect was surgically created in the right tibia of SHR $(\mathrm{n}=12)$ and normotensive rats (NTR; $\mathrm{n}=12)$, while the contralateral tibia was left intact. Eight days later, the animals were sacrificed and the specimens processed in order to obtain decalcified sections. The area of newly-formed bone (NB) within the defect of the right tibia and the TBA in the left tibia were histometrically evaluated. At 8 days post-operative, SHR presented a significantly smaller area of NB when compared to NTR $(\mathrm{p}<0.05)$. In addition, SHR demonstrated a lower TBA than NTR group. In conclusion, the present study demonstrated that SHR rats presented a disturbed bone healing and reduced TBA.
\end{abstract}

Descriptors: Hypertension; Bone remodeling; Bone density; Rats, Inbred SHR.

\section{Introduction}

Human essential hypertension is one of the most prevalent multi-factorial medical conditions, characterized by increased peripheral vascular resistance to blood flow, largely due to vascular remodeling. ${ }^{1}$ Clinical and experimental studies have demonstrated abnormalities in calcium metabolism at the systemic level in hypertension. ${ }^{2,3}$ Essential hypertension may be linked to the increased mobilization of calcium from bone, to the increased losses of calcium from kidney, to the secondary activation of the parathyroid hormone (PTH) and to the angiotensin II activating bone cells. ${ }^{4-7}$

Bone healing is composed of a series of overlapping stages involving the coordinated action of several cell lineages on a cascade of biological events, and has always been one of the most important concerns in medicine and dentistry. The use of some drugs (i.e. corticosteroids, chemotherapeutic agents and anti-inflammatory drugs) and the presence of systemic and environmental factors (i.e. smoking, diabetes and osteoporosis) have been shown to affect bone density and healing. ${ }^{8,9}$ Although the hypothesis that hypertension may have a harmful effect on bone density was previously evaluated in a series of animal and clinical studies, ${ }^{10-}$ 
${ }^{14}$ to date, few investigations have focused on the influence of hypertension on bone healing. ${ }^{15}$

Currently the hypothesis that the hypertension could lead to an increased incidence of late implant loss was evaluated by Alsaadi et al. (2008). ${ }^{16}$ The authors found no significant differences in late failure between normal and hypertensive individuals. ${ }^{16}$ However, the impact of hypertension on early implant failures rate, which is directly related to the wound healing process in the early stage of osseointegration, has never been tested.

Considering the importance of bone quality and healing in several medical and dentistry situations, the aim of this study was to evaluate bone healing and trabecular bone area (TBA) in spontaneously hypertensive rats (SHR), a model of essential hypertension, when compared to normotensive rats (NTR).

\section{Materials and Methods Animals}

The University of Guarulhos Institutional Animal Care and Use Committee previously approved and supervised this study. Twelve male SHR and twelve male Wistar NTR obtained from the Federal University of São Paulo were included in this study. The rats were 150 days of age and weighed approximately $259.93 \pm 44 \mathrm{~g}$ for NTR group and $220.11 \pm 15 \mathrm{~g}$ for SHR group, at the beginning of the study. During the acclimatization (5 days) and experimental periods ( 8 days), animals were housed in groups of four in plastic cages with access to food (Labina, Purina ${ }^{\circledR}$, Paulinia, SP, Brazil) and drinking water ad libitum in the Bioscience Laboratory of Guarulhos University. The rats were kept in a room with a 12 -hour light/dark cycle and temperature between $22^{\circ} \mathrm{C}$ and $24^{\circ} \mathrm{C}$.

\section{Bone healing and density}

After the acclimatization period, general anesthesia was obtained by intraperitoneal administration of xylazine $(10 \mathrm{mg} / \mathrm{kg}$, Virbaxil; Virbac do Brasil Indústria e Comércio, Roseira, SP, Brazil) and ketamine (10 mg/kg, Francotar; Virbac do Brasil Indústria e Comércio, Roseira, SP, Brazil). The skin was cleaned with iodine surgical soap and an incision of approximately $1 \mathrm{~cm}$ in length was made in the upper area of the tibia. Subsequently, a full thickness flap was reflected and the bone surface of the right tibiae was exposed. Under profuse saline solution irrigation, a unicortical circumferential critical-size $\operatorname{defect~}^{17}(3.0 \times 3.0 \mathrm{~mm})$ was drilled on the methaphyseal area of the tibiae with a $3.0 \mathrm{~mm}$ wide trephine bur at a rotary speed not exceeding 1,500 rpm. The bur was introduced in the medullar area to create a drill hole with $3 \mathrm{~mm}$ of height. The soft tissues were then repositioned and sutured to achieve the primary closure [Poly-vycril 5.0 (Ethicon, São Paulo, SP, Brazil) and Silk 4.0 (Ethicon, São Paulo, SP, Brazil)]. The left tibia remained without defect to be used in the analysis of TBA (Figure 1).

\section{Tissue processing}

Animals were euthanized by $\mathrm{CO}_{2}$ inhalation at 8 days after the creation of the bone defect. Both tibia were removed and fixed in $10 \%$ buffered formalin for 48 hours. The specimens were decalcified in a solution containing $10 \%$ ethylene-diamine tetraacetic acid (EDTA), dehydrated in an ascending series of ethanol solution and embedded in paraffin. Semi-serial sections ( $5 \mu \mathrm{m}$ thick) were obtained in a transversal direction and stained with hematoxylin and eosin solutions.

\section{Histometric procedures}

All histometric evaluations were performed using an image analysis system (Image-Pro ${ }^{\circledR}$; Media Cybernetics, Silver Spring, MD, USA) by the same trained, calibrated and blinded examiner. The three most central histological sections of each defect and the three corresponding sections in the tibia without defect were chosen for histometric evaluation. The selected sections were saved as digital images and composite digital figures were created by the combination of two small images. This procedure was performed to permit the view of the entire defect and to obtain images at a better level of magnification for evaluations. For the analysis of bone healing, the total area $\left(\mathrm{TA}, \mathrm{mm}^{2}\right)$ corresponding to medullar area of surgical defect was delineated on the composite image. Subsequently, the newly-formed bone area $\left(\mathrm{NB}, \mathrm{mm}^{2}\right)$ was delineated within the TA. The 
Figure 1 - (A) Defect after healing period with newly-formed bone and the remained defect. (B) Tibia without defect with a checkered diagram used for the analysis of trabecular bone area (TBA). CB: cortical bone; $\mathrm{MB}$ : medullar bone.
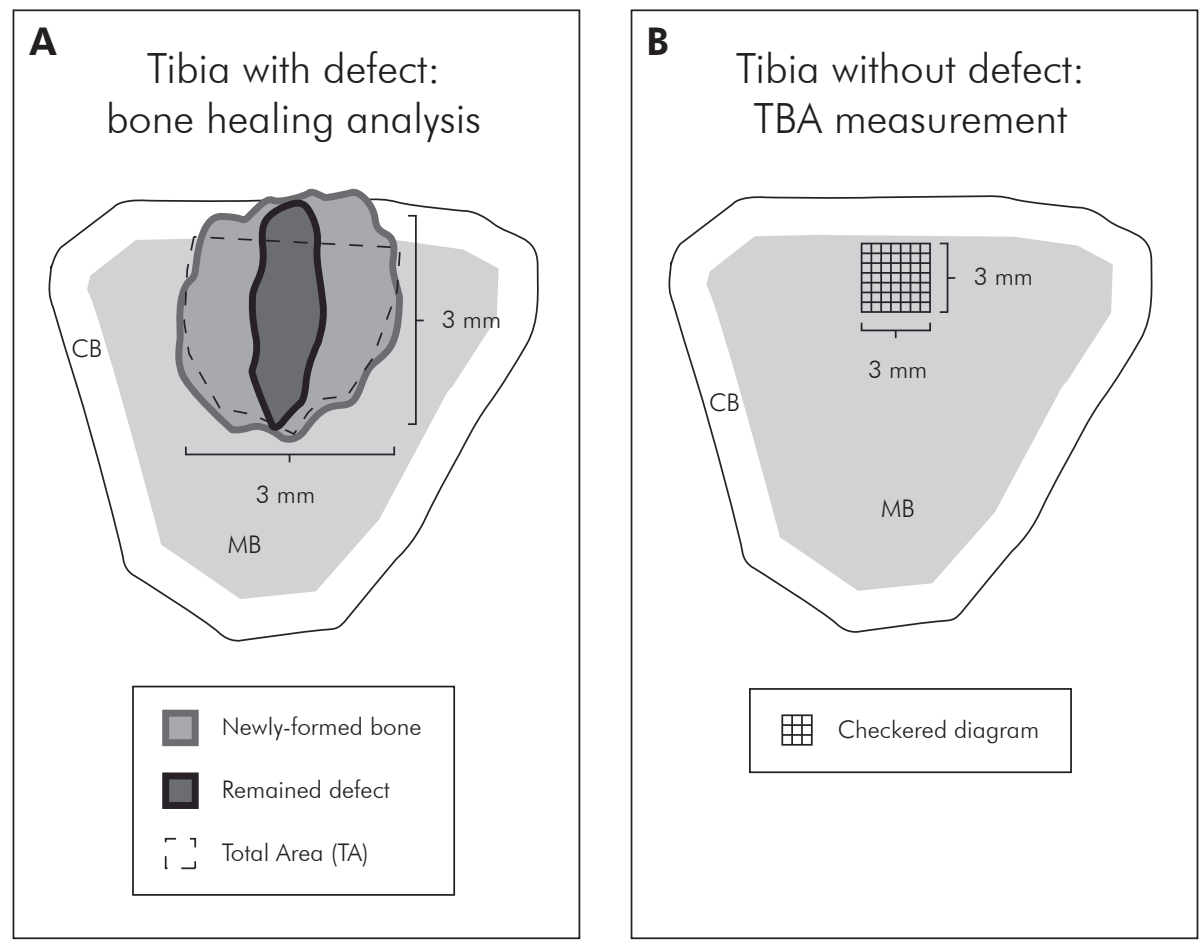

value of TA obtained was considered as $100 \%$ of the defect and the percentage of NB was calculated according to the following formula (Figure 1A):

$$
\frac{\mathrm{NB}\left(\mathrm{mm}^{2}\right) \times 100}{\mathrm{TA}\left(\mathrm{mm}^{2}\right)}
$$

For the analysis of the TBA, a standardized quadrilateral area $\left(1 \mathrm{~mm}^{2}\right)$ was delimited in the medullar area and a checkered diagram was overlaid over this region, constituting a drawing of 314 intersections as illustrated in Figure 1B. The number of intersections, under which the presence of bone tissue was observed, was then counted. The 314 intersections were considered as $100 \%\left(1 \mathrm{~mm}^{2}\right)$ and the TBA was calculated according to the following formula (Figure 1B):

\section{(number of counted intersections) $\times 100$}

$$
314
$$

\section{Statistical analysis}

The mean percentage of NB and TBA of the three sections were averaged for each animal and across animals in the two experimental groups (SHR or NTR). In order to test the hypothesis that the experimental model of hypertension had no influence on
NB and TBA, an intergroup analysis was performed by the Mann-Whitney test. The significance level established for all analyses was $1 \%(\mathrm{p}<0.01)$.

\section{Results}

There were no statistically significant differences between the mean body weights of SHR $(304.1 \pm 17 \mathrm{~g})$ and NTR $(307.9 \pm 54 \mathrm{~g})$ groups at the beginning and at the end of the experimental period $(\mathrm{p}>0.05)$. The mean percentage of TBA was significantly lower in the SHR (15.42 $\pm 4.16 \%)$ when compared to the NTR group $(21.46 \pm 3.96 \%)$ $(\mathrm{p}=0.0026)$, showing that the trabecular bone was negatively influenced by the model of essential hypertension. Figures 2A-2D illustrate the histological findings of TBA for SHR and NTR. Figures 2A and 2C show a low proportion of bone trabeculae with large inter-trabecular spaces in the medullar area of the methaphyseal region in an animal from the SHR group. Figures $2 \mathrm{~B}$ and $2 \mathrm{D}$ illustrate a normal cancellous bone.

The SHR group presented a significantly lower percentage of NB area in the defect $(25.62 \pm 8.56 \%)$ when compared to the NTR group $(86.76 \pm 1.78 \%)$ $(\mathrm{p}<0.0001)$. Figures 3A-3D illustrate the histologi- 

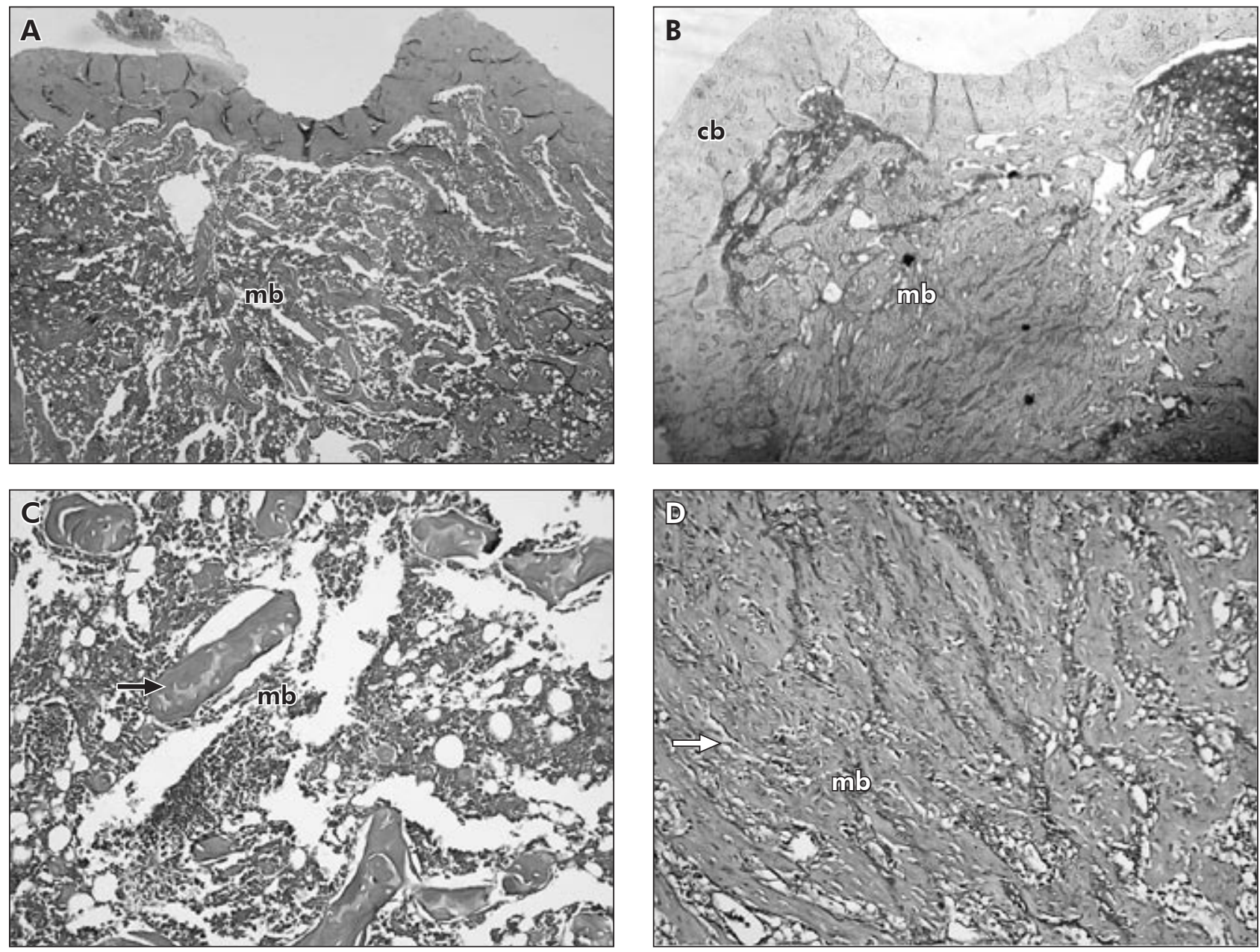

Figure 2 - Photomicrographs illustrating transversal sections of the tibia without defect for SHR (A/C) and NTR (B/D) groups, showing low proportions of bone trabeculae and large inter-trabecular spaces in the medullar area of the SHR group. Lower magnification, $25 \times$ (A/B). Higher magnification, $100 \times$ (C/D). cb: cortical bone; mb: medullar bone; bone trabeculae (arrow).

cal findings of bone healing for SHR and NTR, respectively. Figures $3 \mathrm{~A}$ and $3 \mathrm{C}$ show NB restricted to areas close to the borders of the surgical defect, with immature and poorly organized bone trabeculae from SHR. Figures 3B and 3D present a considerably increased new well-organized bone growth coming from the walls of the defect in the control group.

\section{Discussion}

The outcomes of dental and orthopedic implants and the increased risk of fracture are directly related to bone quality. In addition, successful bone formation after tooth extraction, osseointegration of implants, reconstruction of skeletal defects and fracture repair are totally dependent on an adequate bone healing. As such, the influence of systemic conditions and habits on bone tissue should be considered in order to find the groups with increased risk for deficient bone repair and poor bone density. Thus, the aim of this study was to investigate the influence of hypertension on bone healing and TBA in the tibia of SHR, considered to be a reliable model of essential hypertension.

In the present study, NTR with 150 days of age showed a considerably greater TBA than the agematched SHR. In addition, at 8 days post-operative, the SHR group presented a significantly lower bone formation than that of the NTR group within the surgically-created critical-size defects. Based 

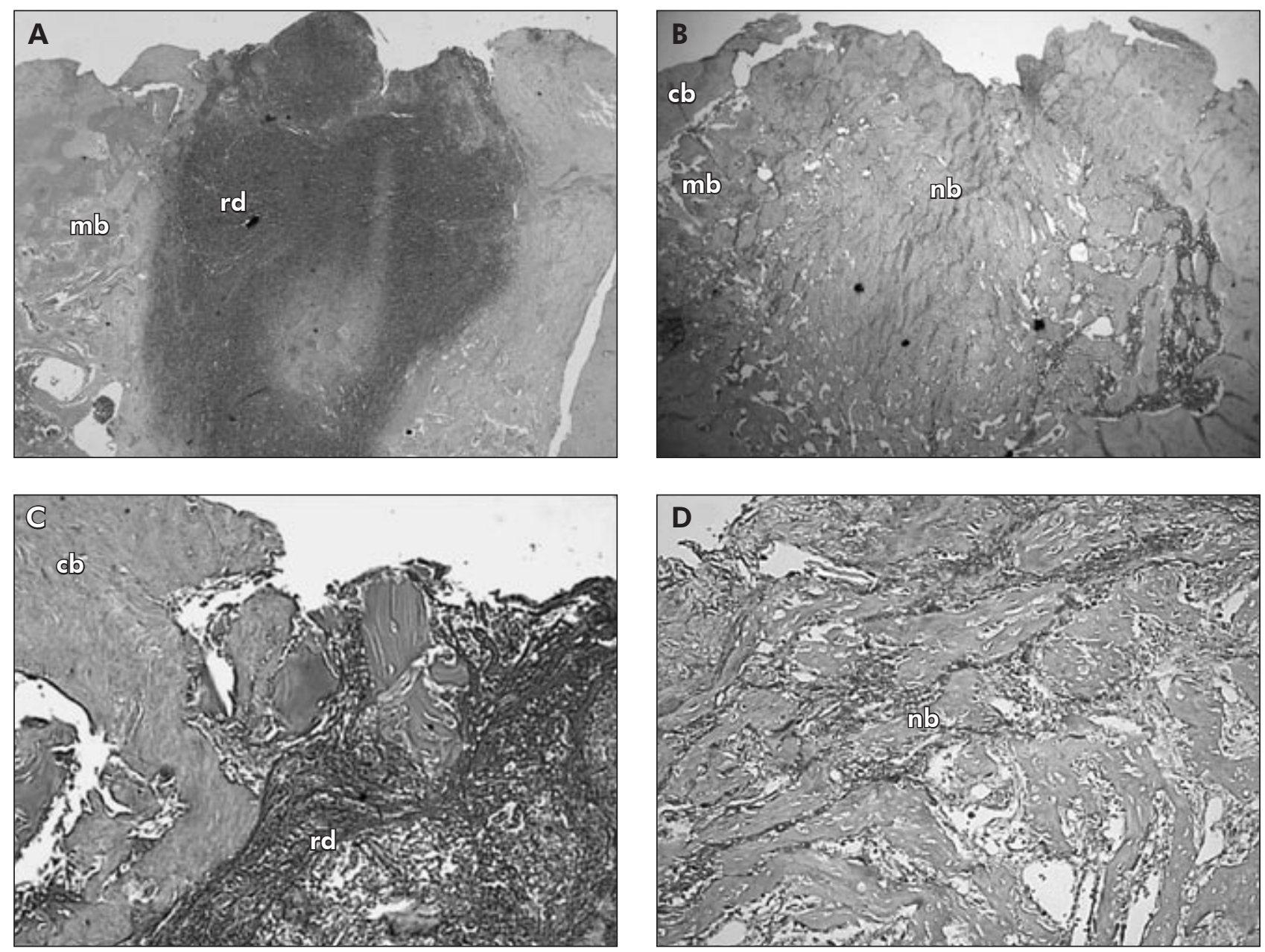

Figure 3 - Photomicrographs illustrating transversal sections of the right tibia with the surgical defect for SHR (A/C) and NTR (B/D) groups. Figure 3A shows newly-formed bone restricted to areas close to the borders of the defect, while figure 3B illustrates a large amount of new bone coming from the walls of the defect. Lower magnification, $25 \times$ (A/B). Higher magnification, $100 \times$ (C/D). cb: cortical bone; mb: medullar bone; nb: newly-formed bone; rd: remained defect.

on these findings, it could be suggested that hypertension affected not only the density of the preexisting bone but also the newly-formed bone tissue of the medullar region. It is important to note that the histometric analyses were performed only in the medullar region of the tibia, excluding the cortical bone. This criterion was chosen based on the fact that medullar bone, which presents a great potential for repair due to the presence of large numbers of bone cells, is more responsive to the influence of risk factors (i.e. osteoporosis, cigarette smoking), especially in short-term experimental periods. ${ }^{8,9}$

The reduced TBA observed in the SHR of the present study is consistent with some previous investigations using the same animal model with differ- ent ranges of age. Metz et al. $(1990)^{18}$ demonstrated that SHR at 6 weeks of age exhibited significantly lower levels of bone density than NTR and that this reduced density can be reverted by supplemental dietary calcium. Barbagallo et al. $(1990)^{19}$ showed that 24-week-old SHR presented a lower bone density and calcium content than age-matched NTR. Similar findings were observed by Barbagallo et al. (1991), ${ }^{20}$ Inoue et al. (1995) ${ }^{21}$ and Wright and DeMoss (2000). ${ }^{12}$

Together, the results of our and these experimental studies support the clinical investigations documenting an association between low bone mineral density (BMD) and high blood pressure. Cappuccio et al.(1999), ${ }^{2}$ evaluating 3,676 women, showed that 
elevated blood pressure in elderly white women was associated with increased bone loss at the femoral neck. Similarly, Tsuda et al. $(2001)^{3}$ observed by means of dual-energy X-ray absorptiometry a significant decrease in BMD in female hypertensive compared with normotensive women. Gotoh et al. $(2005)^{13}$ demonstrated that the BMD in the lumbar spine in women with normotension was higher than that of women with essential hypertension. Although the precise pathophysiological mechanisms by which hypertension could have a harmful effect on bone density are still unclear. Some suggested hypotheses include changes in PTH and calcium metabolism and the role of angiotensin II in bone cells. Angiotensin II is the major mediator of the maintenance of extracellular fluid volume and blood pressure and may decelerate osteoblastic differentiation and bone formation and activate osteoclasts and bone resorption. . $^{-7,21-23}$

Although some studies have already reported the influence of hypertension on bone density, the results of the present study contribute to the original information regarding the negative effect of hypertension on the early stages of bone healing in a surgicallycreated critical-size defect. A mechanism that could partially explain our histometric results may also be attributed to the influence of angiotensin II on bone cells. Although the effect of angiotensin II on osteoblastic cells is still controversial and predominantly based on in vitro studies, ${ }^{23-25}$ there is some evidence to suggest that this mediator is a potent suppressor of the differentiation of osteoblastic cells and, consequently, of the bone formation by these cells. ${ }^{22}$ Our findings are contradictory to those described

\section{References}

1. Virdis A, Ghiadoni L, Versari D, Giannarelli C, Salvetti A, Taddei S. Endothelial function assessment in complicated hypertension. Curr Pharm Des. 2008;14(18):1761-70.

2. Cappuccio FP, Meilahn E, Zmuda JM, Cauley JA. High blood pressure and bone-mineral loss in elderly white women: a prospective study. Study of Osteoporotic Fractures. Lancet. 1999 Sep 18;354(9183):971-5.

3. Tsuda K, Nishio I, Masuyama Y. Bone mineral density in women with essential hypertension. Am J Hypertens. 2001 Jul;14(7 Pt 1):704-7. by Pereira et al. (2007), ${ }^{15}$ in which the amount of newly-formed bone was similar in SHR and NTR animals at 7 days and higher in SHR at 21 days post-operative. In addition to the differences in the experimental periods between this study and ours, these conflicting results may also be explained by dissimilarities in rat age (data not shown) and gender (male and female) and by the localization (femur diaphysis) and size $(2 \mathrm{~mm})$ of the defects. The use of the critical-size defect is important to evaluate the real impact of local and systemic factors that could influence bone healing. Lewandrowski et al. (1999) ${ }^{17}$ observed that a surgically created defect of $3 \mathrm{~mm}$ in diameter in rat tibia did not heal spontaneously in up to 7 weeks post-operative, being an appropriate model for evaluations of the newly-formed bone.

\section{Conclusion}

The results of the present study demonstrated that SHR rats presented an impairment of bone healing and reduced TBA, indicating that individuals with essential hypertension could be a risk group for these bone disorders. Nevertheless, further studies should be considered in order to clinically evaluate the relevance of our findings.

\section{Acknowledgment}

The authors greatly appreciated the assistance of the lab technicians from Guarulhos University: Paulo César Simões Silva, for helping with the histological procedures and, Rogério Tadeu Barreira, for technical support with animal care. There is no conflict of interest to declare.

4. McCarron DA, Pingree PA, Rubin RJ, Gaucher SM, Molitch M, Krutzik S. Enhanced parathyroid function in essential hypertension: a homeostatic response to a urinary calcium leak. Hypertension. 1980 Mar-Apr;2(2):162-8.

5. Strazzullo P, Trevisan M, Farinaro E, Cappuccio FP, Ferrara LA, de Campora E, et al. Characteristics of the association between salt intake and blood pressure in a sample of male working population in southern Italy. Eur Heart J. 1983 Sep;4(9):608-13. 
6. Young EW, McCarron DA, Morris CD. Calcium regulating hormones in essential hypertension. Importance of gender. Am J Hypertens. 1990 Aug;3(8 Pt 2):161S-166S.

7. Oshima T, Young EW. Systemic and cellular calcium metabolism and hypertension. Semin Nephrol. 1995 Nov;15 (6):496-503.

8. Duarte PM, César Neto JB, Gonçalves PF, Sallum EA, Nociti FH. Estrogen deficiency affects bone healing around titanium implants: a histometric study in rats. Implant Dent. 2003;12(4):340-6.

9. César-Neto JB, Duarte PM, Sallum EA, Barbieri D, Moreno H Jr, Nociti FH Jr. A comparative study on the effect of nicotine administration and cigarette smoke inhalation on bone healing around titanium implants.J Periodontol. 2003 Oct;74(10):1454-9.

10. Izawa Y, Sagara K, Kadota T, Makita T. Bone disorders in spontaneously hypertensive rat. Calcif Tissue Int. 1985 Dec;37(6):605-7.

11. Liang H, Ma Y, Pun S, Stimpel M, Jee WS. Aging- and ovariectomy-related skeletal changes in spontaneously hypertensive rats. Anat Rec. 1997 Oct;249(2):173-80.

12. Wright GL, DeMoss D. Evidence for dramatically increased bone turnover in spontaneously hypertensive rats. Metabolism. 2000 Sep;49(9):1130-3.

13. Gotoh M, Mizuno K, Ono Y, Takahashi M. High blood pressure, bone-mineral loss and insulin resistance in women. Hypertens Res. 2005 Jul;28(7):565-70.

14. Mussolino ME, Gillum RF. Bone mineral density and hypertension prevalence in postmenopausal women: results from the Third National Health and Nutrition Examination Survey. Ann Epidemiol. 2006 May;16(5):395-9.

15. Pereira AC, Fernandes RG, Carvalho YR, Balducci I, FaigLeite $\mathrm{H}$. Bone healing in drill hole defects in spontaneously hypertensive male and female rats' femurs. A histological and histometric study. Arq Bras Cardiol. 2007 Jan;88(1):104-9.

16. Alsaadi G, Quirynen M, Komárek A, van Steenberghe D. Impact of local and systemic factors on the incidence of late oral implant loss. Clin Oral Implants Res. 2008 Jul; 19(7):6706.

17. Lewandrowski KU, Cattaneo MV, Gresser JD, Wise DL, White RL, Bonassar L, et al. Effect of a poly(propylene fumarate) foaming cement on the healing of bone defects. Tissue Eng. 1999 Aug;5(4):305-16.

18. Metz JA, Karanja N, Young EW, Morris CD, McCarron DA. Bone mineral density in spontaneous hypertension: differential effects of dietary calcium and sodium. Am J Med Sci. 1990 Oct;300(4):225-30.

19. Barbagallo M, Raddino R, Restori G, Boiardi L, Novo S, Strano A. Alterations of calcium metabolism in spontaneously hypertensive rats. Cardioscience. 1990 Jun;1(2):105-7.

20. Barbagallo M, Quaini F, Baroni MC, Barbagallo CM, Boiardi L, Passeri G, et al. Histological evidence of increased turnover in bone from spontaneously hypertensive rats. Cardioscience. 1991 Mar;2(1):15-7.

21. Inoue T, Moriya A, Goto K, Tanaka T, Inazu M. What is the difference of bone growth in SHR and SD rats? Clin Exp Pharmacol Physiol Suppl. 1995 Dec;22(1):S242-3.

22. Hatton R, Stimpel M, Chambers TJ. Angiotensin II is generated from angiotensin I by bone cells and stimulates osteoclastic bone resorption in vitro. J Endocrinol. 1997 Jan;152(1):510.

23. Hagiwara H, Hiruma Y, Inoue A, Yamaguchi A, Hirose S. Deceleration by angiotensin II of the differentiation and bone formation of rat calvarial osteoblastic cells. J Endocrinol. 1998 Mar;156(3):543-50.

24. Shimizu H, Nakagami H, Osako MK, Hanayama R, Kunugiza Y, Kizawa T, et al. Angiotensin II accelerates osteoporosis by activating osteoclasts. FASEB J. 2008 Jul;22(7):2465-75.

25. Hiruma Y, Inoue A, Hirose S, Hagiwara H. Angiotensin II stimulates the proliferation of osteoblast-rich populations of cells from rat calvariae. Biochem Biophys Res Commun. 1997 Jan 3;230(1):176-8. 